\title{
Oncologia Pediátrica e Investigações Científicas em População Vulnerável
}

doi: https://doi.org/10.32635/2176-9745.RBC.2018v64n3.24

Pediatric Oncology and Scientific Investigations in Vulnerable Population
Oncología Pediátrica e Investigaciones Científicas en Población Vulnerable

Maria S. Pombo-de-Oliveira'

No contexto populacional, as neoplasias pediátricas são doenças raras e, como tal, são menos exploradas em pesquisas de saúde pública que buscam agentes causais de câncer. A história natural de uma neoplasia maligna se fortalece por meio de evidências numericamente robustas na incidência e mortalidade e seu impacto em uma população de risco. O exemplo clássico é o câncer de pulmão, cujas pesquisas e resultados científicos desenvolvidos nas últimas três décadas culminaram com um grande sucesso no tratamento e nos programas preventivos da doença. No entanto, historicamente, o desvendar de uma neoplasia rara é de suma importância nos estudos de carcinogênese. Como exemplo, podemos citar as leucemias agudas na primeira infância, o retinoblastoma, meduloblastomas e o carcinoma vaginal de células claras, cujas investigaçôes resultaram em grande sucesso nos tratamentos oncológicos em geral. As neoplasias pediátricas são cada vez mais investigadas e desvendadas quanto à biologia celular e às consequências das lesôes genéticas que geram clone neoplásico (leucêmico e/ou tumoral). A diversidade e a complexidade de cada tipo de leucemia e/ou tumor embrionário (p.ex., meduloblastoma) estimulam os desafios atuais no âmbito da biotecnologia, com incessantes buscas para a melhor compreensão da multiplicidade clínica das neoplasias pediátricas. Atualmente, o conhecimento adquirido sobre os mecanismos celulares e moleculares, que segregam subgrupos de doenças com a mesma denominação histopatológica, são alvo de intervençôes terapêuticas específicas.

Em termos epidemiológicos, muito pouco se conhece sobre as neoplasias pediátricas no Brasil. Como os países de baixo e médio desenvolvimento estão em transição epidemiológica nas áreas de doenças infecciosas e não transmissíveis, o tratamento do câncer pediátrico se tornou um foco de interesse global ${ }^{1}$.

As leucemias agudas são os tipos mais comuns de câncer infantil. Embora com termos comuns como "leucemia linfoide" ou "mieloide" (linfoides, LLA e mieloides, LMA), as leucemias são muito heterogêneas com vários subtipos de aspectos morfológicos (celulares) distintos e alteraçóes moleculares, que são determinantes para o tratamento, previsão de repostas clínicas e sobrevida global, e fatores de riscos etiopatológicos ${ }^{2-4}$. Atualmente, o mapeamento genômico de tumores tem um grande potencial para definição de terapias dirigidas ao clone maligno ${ }^{5}$. Outro grande avanço na terapia oncológica foi o crescimento da imunoterapia com os sucessos clínicos obtidos, o bloqueio de ação de vias celulares (checkpoint imunológico) e terapias com células $\mathrm{T}$ de receptor de antígeno quimérico. Esses sucessos também ressaltam a importância da compreensão da imunologia básica do tumor para uma tradução clínica bem-sucedida no tratamento de crianças com câncer ${ }^{6}$.

Este volume da Revista Brasileira de Cancerologia (RBC) divulga trabalhos realizados em câncer pediátrico, a partir de diferentes abordagens multidisciplinares e clínicas resultantes de experiências individuais de diversas regiōes do Brasil. Talvez a mensagem mais importante desta edição seja mostrar que estamos tentando construir a história natural de tumores pediátricos por meio de investigaçóes realizadas em Centros de referência de tratamento de tumores pediátricos. Porém, nos vários artigos desta edição, destaca-se a necessidade de se realizar estudos multicêntricos, multidisciplinares e interdisciplinares. Sem essas características, hoje seria muito difícil tirar conclusôes relevantes sobre o comportamento da neoplasia infantil no Brasil e nos países em desenvolvimento. Especial ênfase às pesquisas com registro de câncer de base populacional, que se destinam a retratar o problema no âmbito populacional. Em razão da vulnerabilidade das crianças, se faz urgentemente necessária, também, a elaboração de estudos epidemiológicos (leucemias e tumores embrionários), incluindo biomarcadores genético-moleculares associados aos fatores ambientais, cujos aspectos estão relacionados primariamente à exposiçâo parental, como vem sendo feito em consórcio de estudos internacionais ${ }^{7}$.

Embora em muitos casos de leucemias agudas ou tumores embrionários não seja identificada nenhuma predisposição genética específica, essas doenças têm reconhecidamente uma base genética nas suas raízes de origem. Tumores

'Instituto Nacional de Câncer José Alencar Gomes da Silva (INCA). E-mail: mpombo@inca.gov.br. Orcid iD: http://orcid.org/0000-0003-3986-8993

Endereço para correspondência: Maria S. Pombo-de-Oliveira. Centro de Pesquisa, Divisão de Medicina Experimental, INCA. Rua André Cavalcanti, 37 - Centro. Rio de Janeiro (RJ), Brasil. CEP 20231-050. 
embrionários, como neuroblastoma, retinoblastoma e tumor de Wilms, são associados a mutações germinativas em TP53, WT1, RB1 e CDKN, ou à presença de anomalias congênitas. Leucemias agudas na primeira infância têm origem na vida intrauterina ${ }^{3,4}$. De qualquer maneira, as alterações genéticas recorrentes são o "pivot" da tumorgênese e de grande relevância nos diagnósticos e tratamentos ${ }^{5,8}$. As alteraçōes citogenéticas-moleculares que são restritas ao clone neoplásico, tais como as translocações, inversōes, deleçôes, amplificação gênica e mutações pontuais, já são consideradas como mandatórias na caracterização das leucemias agudas, nos linfomas e em meduloblastoma, antes de qualquer conduta terapêutica. Portanto, faz-se necessário o treinamento continuado do profissional que abraça o tratamento de tumores pediátricos. $\mathrm{O}$ trabalho interdisciplinar entre um especialista médico, uma enfermeira, um biomédico, um biólogo molecular é de suma importância no sucesso do tratamento oncológico. Em especial, buscar, por intermédio da investigação interdisciplinar, o maior uso das ferramentas biotecnológicas disponíveis para identificar os pacientes que serâo resgatados com tratamento específicos pela medicina de precisão $0^{8,9}$. Não esquecendo que a atenção à qualidade médica e do tratamento são os fatores mais influentes na evolução e sobrevida de crianças e adolescentes com tumores pediátricos. Existem crianças em países pobres que têm resultados favoráveis da doença, independentemente da limitação de recursos, pelo fato de esses países terem desenvolvido programas multi-institucionais.

Recentemente, com a formação de consórcios de pesquisas, surgiu uma nova geração de informaçóes consistentes entre as diferentes etapas dos mecanismos de patogênese nos níveis da biologia celular, da relação genômica-epigenética, e da evolução de clone tumoral, sendo possível estabelecer associaçôes de riscos com potenciais agentes "causais" de leucemias agudas e em alguns tumores pediátricos ${ }^{10}$. Dessa forma, será possível, e podemos ser otimistas quanto a estabelecer programas preditivos de evolução de doença, ou desenvolver medidas de aferição precisa de carga tumoral e, por que não, medidas de prevençáo de tumores.

A partir deste volume da RBC, poderemos mostrar que os tumores pediátricos, independentemente de sua raridade, têm impacto nos estudos de carcinogênese, nas abordagens terapêuticas e mortalidade infantil e na qualidade de vida dos sobreviventes.

\section{REFERÊNCIAS}

1. Bhakta N, Force LM, Allemani C, Atun R, Bray F, Coleman MP, et al. Childhood cancer burden: a review of global estimates. Lancet Oncol. 2019;20(1): e42-e53. doi:https://doi.org/10.1016/S1470-2045(18)30761-7.

2. Bhojwani D, Yang JJ, Pui CH. Biology of childhood acute lymphoblastic leukemia. Pediatr Clin North Am. 2015;62(1): 47-60. doi:10.1016/j.pcl.2014.09.004.

3. Greaves M. A causal mechanism for childhood acute lymphoblastic leukaemia. Nat Rev Cancer. 2018 Aug; 18(8):471484. doi:10.1038/s41568-018-0015-6.

4. Pombo-de-Oliveira MS, Andrade FG; Brazilian Collaborative Study Group of Infant Acute Leukemia. early-age acute leukemia: revisiting two decades of the Brazilian collaborative study group. Arch Med Res. 2016 Nov;47(8):593-606. doi:10.1016/j.arcmed.2016.11.014. Review.

5. Connolly JJ, Hakonarson H. The impact of genomics on pediatric research and medicine. Pediatrics. 2012;129(6):11501160. doi:10.1542/peds.2011-3636.

6. Couzin-Frankel J. Cancer immunotherapy. Science. 2013; 342(6165):1432-1433. doi:10.1126/science.342.6165.1432. Spec No Breakthrough of the year.

7. Tikellis G, Dwyer T, Paltiel O, Phillips GS, Lemeshow S, et al. The international childhood cancer cohort consortium (I4C): a research platform of prospective cohorts for studying the aetiology of childhood cancers. Paediatr Perinat Epidemiol. 2018;32(6):568-583. doi:10.1111/ppe.12519.

8. Gröbner SN, Worst BC, Weischenfeldt J, Buchhalter I, Kleinheinz K, Rudneva VA, et al. The landscape of genomic alterations across childhood cancers. Nature. 2018 Mar 15;555(7696):321-327. doi: 10.1038/nature25480.

9. Forrest SJ, Geoerger B, Janeway KA. Precision medicine in pediatric oncology. Curr Opin Pediatr. 2018 Feb;30(1):1724. doi:10.1097/MOP.0000000000000570.

10. Whitehead TP, Metayer C, Wiemels JL, Singer AW, Miller MD. Childhood leukemia and primary prevention. Curr Probl Pediatr Adolesc Health Care. 2016 Oct;46(10):317-352. doi: 10.1016/j.cppeds.2016.08.004. 